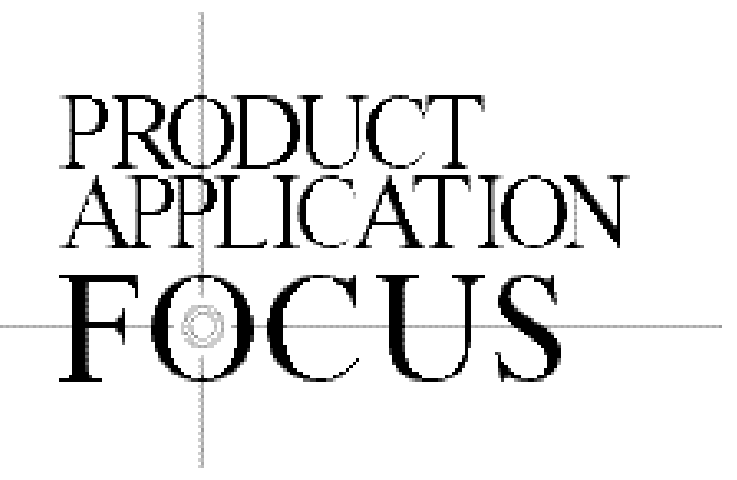

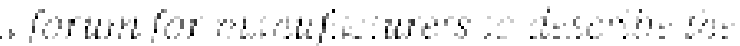

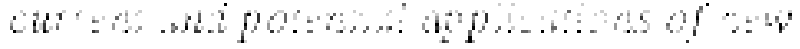

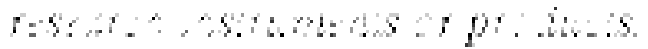

\title{
Analysis of Microliter Volumes of Dye-Labeled Nucleic Acids
}

\author{
Tateo Nagai and William H. Chapman Jr. \\ MiraiBio, Alameda, CA, USA
}

BioTechniques 32:356-364 (February 2002)

\begin{abstract}
We describe methodology useful for determining the fluorescent activity of small volumes (e.g., $1 \mu L)$ of dye-labeled cDNAs using microabsorbance spectroscopy. A direct relationship was found between the average fluorescent hybridization signal from an array and the fluorescent activity of the cDNA used in the hybridization. The microabsorbance method makes possible the screening of small-volume samples before hybridization, allowing for a more efficient use of available microarrays. The standardization of the concentration of RNA samples contained in $1 \mu L$ before reverse transcription is also described.
\end{abstract}

\section{INTRODUCTION}

Hybridization to nucleic acid arrays has proven to be an effective method for the analysis of large populations of mRNA sequences contained in almost any biological sample $(3-7,9,10)$. Since the hybridization to an array under a coverslip requires only microliter volumes of hybridization solution, array assays can be used to analyze nucleic acid samples that are available only in small quantities, such as RNA isolated from laser-microdissected tissue sam ples (6) or small batches of cells produced by immunochemical fractionation (e.g., fluorescence-activated cell sorting).

The reproducibility of microarray hybridization signals from day to day requires well-controlled preparation and analysis of the dye-labeled cDNA samples. This includes standardization of the concentration of the RNA sample to be reverse transcribed and, after the reverse transcription, measurement of the fluorescence activity (number of dye molecules/DNA base). Since the sample volumes used in microarray experiments are often very small (e.g., 1 $\mu \mathrm{L}$ ), these data have been very difficult to obtain. In this report, we demonstrate the utility of a microabsorbance spectrometer, the GeneSpec ${ }^{\mathrm{TM}}$ III (available from MiraiBio, Alameda, CA, USA), in the measurement of the concentration of nucleic acids and dye labels contained in samples as small in volume as $1 \mu \mathrm{L}$ (2). The fluorescent activity of two different cDNA labeling methods was measured, and the results are compared to the relative signal strength obtained after hybridization to a complementary cDNA microarray. The average hybridization signal observed in the microarray experiment correlates well with the simple GeneSpec III measurement.

\section{MATERIALS AND METHODS}

\section{Microabsorbance Measurements}

The GeneSpec III is designed for the analysis of small volumes of aqueous samples for absorbance of light in the 
wavelength range of 190-1100 $\mathrm{nm}$. In this report, the GeneSpec III was used to measure concentrations of nucleic acid samples and fluorescent dyes to guide the preparation of a microarray hybridization experiment. The errors in all measurements reported here were calculated from error functions established for Cy3dUTP, Cy5dUTP, and ssDNA (5'-GCCGATGGTTGAAT-3'). The species of interest was serially diluted in water, and its absorbance spectrum at each concentration was measured four times. The $\mathrm{CV}$ of the replicate

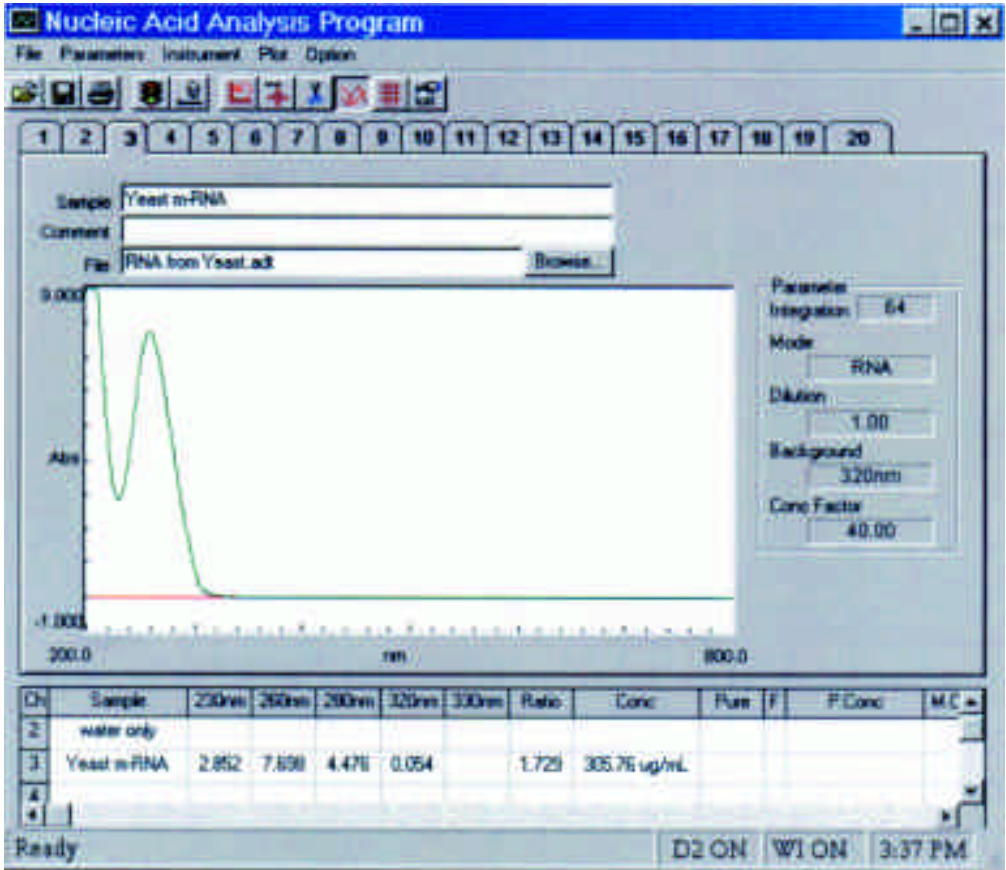

Figure 1. Absorbance spectra of an mRNA sample (S. cerevisiae, strain DBY746) recorded in a 1- $\mu \mathrm{L}$ volume cuvet with the GeneSpec III.

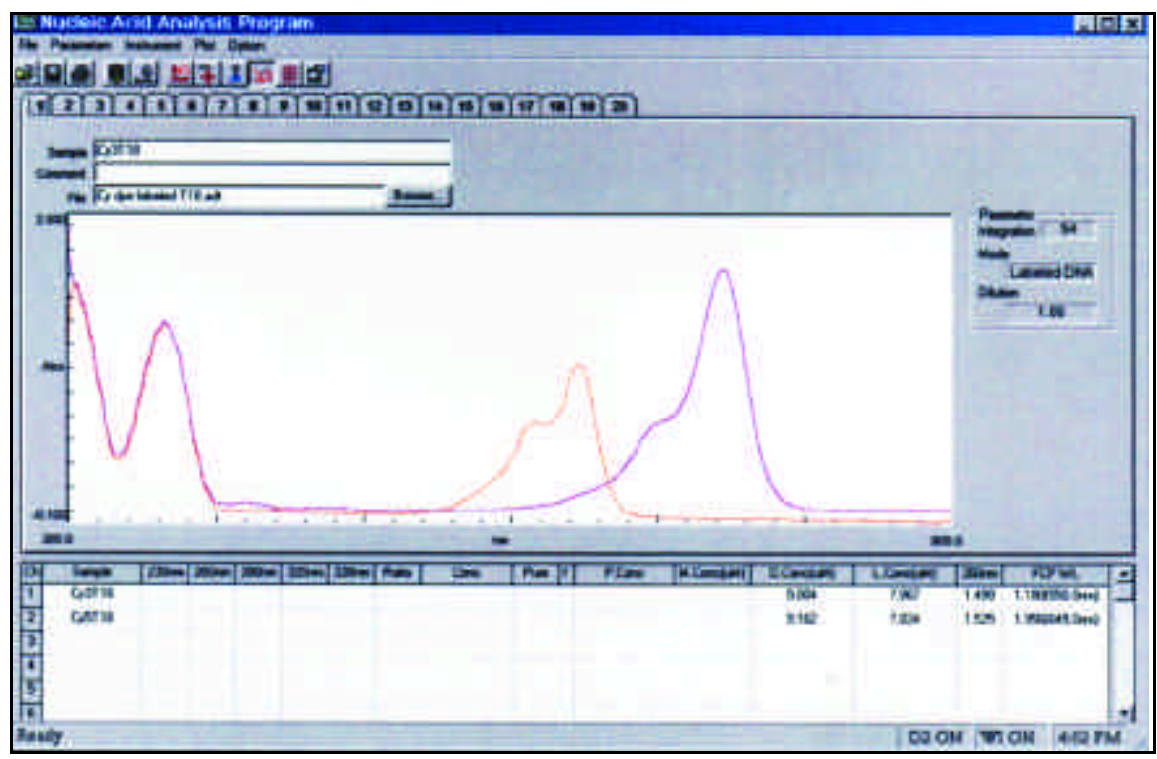

Figure 2. Absorbance spectra (1- $\mu \mathrm{L}$ cuvet, GeneSpec III) of both Cy3- and Cy5-labeled primers that were used for the reverse transcription of the mRNA whose spectra are shown in Figure 1. data and the concentration of the sample was fit to Equation 1 (Microsoft ${ }^{\circledR}$ Excel $^{\circledR}$; see Reference 2 for more examples). Table 1 lists the parameters (a and $b$ ) of Equation 1 determined for each of the three species studied. The concentration of nucleic acid bases used for the calculation of the labeling efficiency is calculated from the average extinction coefficient of a nucleic acid base. The extinction coefficients of the nucleic acid bases used for these calculations were averages of values obtained from a number of references $(1,8)\left(\mathrm{A}=15400 \mathrm{M}^{-1} \mathrm{c} \mathrm{m}^{-1} ; \mathrm{C}=7500\right.$ $\mathrm{M}^{-1} \mathrm{c} \mathrm{m}^{-1} ; \mathrm{G}=11700 \mathrm{M}^{-1} \mathrm{c} \mathrm{m}^{-1} ; \mathrm{T}=$ $9200 \mathrm{M}^{-1} \mathrm{c} \mathrm{m}^{-1}$ ) and are the default parameters in the GeneSpec III software. The concentration factors used for the calculation of the concentration of nucleic acids were $33 \mu \mathrm{g} / \mathrm{mL}$ ssDNA, 50 $\mu \mathrm{g} / \mathrm{mL}$ dsDNA, and $40 \mu \mathrm{g} / \mathrm{mL}$ RNA (1). The molar extinction coefficients of Cy3 (150000 M-1 $\mathrm{c} \mathrm{m}^{-1}$ at $\left.550 \mathrm{~nm}\right)$ and Cy5 (250000 $\mathrm{M}^{-1} \mathrm{~cm}^{-1}$ at $\left.649 \mathrm{~nm}\right)$ triphosphates were obtained from Amersham Biosciences technical data sheets (Piscataway, NJ, USA).

$$
\mathrm{CV}=\mathrm{a}(\text { concentration })^{\wedge} \mathrm{b}
$$

The absorbance of the uracil base in the triphosphates was measured at 260 $\mathrm{nm}$, and the concentration calculated (assuming the extinction coefficient of $9200 \mathrm{M}^{-1} \mathrm{c} \mathrm{m}^{-1}$ ) was found to be approximately equal to the concentration of the Cy dye measured at the longer wavelength $([\mathrm{Cy} 3]=35 \mu \mathrm{M},[\mathrm{dU}]=30$ $\mu \mathrm{M}$ and $[\mathrm{Cy} 5]=35 \mu \mathrm{M},[\mathrm{dU}]=36$ $\mu \mathrm{M})$. Since the molar ratio of the $\mathrm{Cy}$ dye to the uracil base must be one in the triphosphate, the extinction coefficient of the Cy dyes is effectively zero at 260 $\mathrm{nm}$. The maximum absorbance of these triphosphates in the UV is $290 \mathrm{~nm}$, not $260 \mathrm{~nm}$. The shift in wavelength appears to be accompanied by an increase in the molar extinction coefficient of the base, although we do not know if all absorbance at $260 \mathrm{~nm}$ is due to this increased extinction coefficient. Indeed, the equivalence of the extinction coefficients at $260 \mathrm{~nm}$ for the modified and unmodified uracil bases would be a strange coincidence. It could be that the extinction coefficient of the uracil base is very small at $260 \mathrm{~nm}$ and the measured absorbance is due to the Cy dye 
or an impurity present in the sample. However, the assignment of this absorbance should not influence the interpretation of the data presented here or on in any other microarray application.

\section{Microarray Protocols}

For a complete description of the microarray protocol on which this work is based, see the protocol section of "The Brown Lab" Web page (http:// cmgm.stanford.edu/pbrown/).

\section{Reverse Transcription of the RNA}

The mRNA ( $2 \mu \mathrm{g} /$ reaction) isolated from Saccharomyces cerevisiae (strain DBY746; Stratagene, La Jolla, CA, USA) was reverse transcribed with

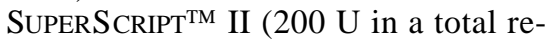
action volume of $20 \mu \mathrm{L}$ ) (Invitrogen, Carlsbad, CA, USA) using three different reverse transcribed primers: $(i)$ Cy3-labeled $\mathrm{T}_{18}$, (ii) Cy5-labeled $\mathrm{T}_{18}$, and (iii) unlabeled $\mathrm{T}_{18}$. All oligonucleotides used were purchased from Operon Technologies (Alameda, CA, USA) and were HPLC purified (see Figure 2 for spectra). Either Cy3- or Cy5-labeled dUTP was included in the reactions run with the unlabeled primers. The concentration of the RNA was determined before the labeling reaction by an absorbance measurement in a $1-\mu \mathrm{L}$ cuvet (1-mm pathlength) (Figure 1). The concentration of the RNA was calculated from the absorbance measured at $260 \mathrm{~nm}$ and the concentration factor $40 \mu \mathrm{g} / \mathrm{mL}$. From the concentration of the RNA calculated from the absorbance measurement $(305.76 \mu \mathrm{g} / \mathrm{mL}, \sigma=0.70)$, the exact volume of RNA solution used for the reverse transcription can be calculated (in this case, $6.54 \mu \mathrm{L}$ corresponds to the desired mass). After the reaction was complete, sodium hydroxide was added to the mixtures to degrade the excess RNA $\left(1 \mathrm{~h}\right.$ at $\left.60^{\circ} \mathrm{C}\right)$, and the samples were purified by size exclusion filtration (Microcon ${ }^{\mathrm{TM}}-30$; Millipore, Bedford, MA, USA). The efficiency of the purification was determined by filtration of mock reverse transcription reactions that did not include the RNA or the reverse transcriptase. Spectra of the dye containing mixture were recorded before
Table 1. Parameters Necessary for the Calculation of the $\mathrm{CV}$ of a GeneSpec III Measurement From the Measured Concentration Using Equation 1

\begin{tabular}{|lcccc|}
\hline $\begin{array}{l}\text { Substance } \\
\text { Analyzed }\end{array}$ & $\mathbf{a}$ & $\mathbf{b}$ & $\begin{array}{c}\text { Concentration } \\
\text { Units }\end{array}$ & $\begin{array}{c}\text { Cuvet Volume } \\
(\mu \mathrm{L})\end{array}$ \\
\hline Cy3dUTP & $3 e-6$ & -0.7746 & molar & 2 \\
Cy5dUTP & $1 e-6$ & -0.8926 & molar & 2 \\
ssDNA & $2 e-5$ & -0.6499 & molar & 2 \\
ssDNA & 0.0621 & -0.2547 & $\mu \mathrm{g} / \mathrm{mL}$ & 2 \\
RNA & 0.1756 & -0.7579 & $\mu \mathrm{g} / \mathrm{mL}$ & 1 \\
\hline
\end{tabular}

and after filtration with the $1-\mu \mathrm{L}$ cuvet and showed that, after filtering $750 \mu \mathrm{L}$ TE through the Microcon-30 (3 aliquots of $250 \mu \mathrm{L}$ each), no dye could be detected in the retained fraction.

The concentration of the labeled cDNA, the fluorescent dye, and the nucleic acid base was determined by absorbance with the GeneSpec III absorbance spectrometer using a $2-\mu \mathrm{L}$ cuvet (2-mm pathlength) (Figures 3 and 4). The concentration of the dye (Cy3 or Cy5) was calculated from its absorbance at the reported absorbance maximum and the appropriate molar extinction coefficient. The concentration of the DNA is calculated from the absorbance at $260 \mathrm{~nm}$ after subtracting the absorbance at $260 \mathrm{~nm}$ attributed to the dye. The absorbance of the dye at $260 \mathrm{~nm}$ is calculated from the concentration of the dye and the reported molar extinction coefficient of the dye at $260 \mathrm{~nm}$. In this case, the dye does not absorb appreciably at $260 \mathrm{~nm}$, and the correction is ignored. Most fluorescent dyes used to label DNA do absorb at $260 \mathrm{~nm}$, and the molar extinction coefficients are known. The final concentration of the DNA is reported in $\mu \mathrm{g} / \mathrm{mL}$ and $\mu \mathrm{M}$, where the molar concentration refers to the concentration of the nucleic acid base present in the sample. The efficiency of the labeling experiment is calculated from the molar concentration of the DNA and the dye (Table 2).

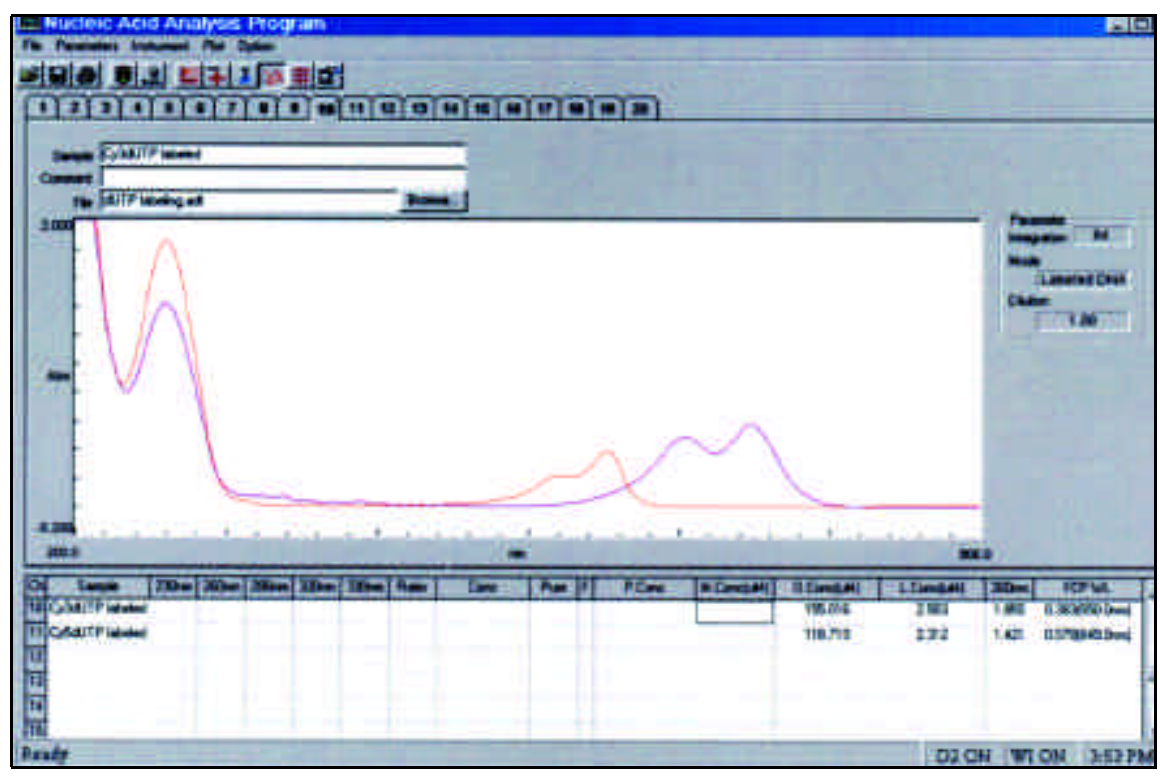

Figure 3. Absorbance spectra ( $2-\mu \mathrm{L}$ cuvet, GeneSpec III) of the cDNA product of the reverse transcription of the yeast mRNA with Cy3-labeled (red line) and Cy5-labeled (blue line) triphosphates. The data column named $\mathrm{O}$. Conc. $(\mu \mathrm{M})$ lists the concentration of the nucleic acid base in each sample (see text for description of the calculation). The data column named L. Conc. $(\mu \mathrm{M})$ lists the concentration of the dye label. The ratio of the two concentrations O. Conc./L. Conc. is a measure of the labeling efficiency of the reverse transcription reaction used to make the cDNA. 
Table 2. Comparison of the Labeling Efficiency of Reverse Transcription Reactions to the Average Fluorescent Hybridization Signal Intensity

\begin{tabular}{|c|c|c|c|c|}
\hline Label & [Bases]/[Cу3] & [Bases]/[Cy5] & $\begin{array}{c}532 \text { Mean Intensity } \\
\text { (RLU) }\end{array}$ & $\begin{array}{c}635 \text { Mean Intensity } \\
\text { (RLU) }\end{array}$ \\
\hline CydUTP & 60.7 & 51.4 & $736 \pm 83.5$ & $1292 \pm 210$ \\
\hline Cy-T 18 & 141.9 & 163.2 & $267 \pm 48.5$ & $189 \pm 81$ \\
\hline
\end{tabular}

\section{Printing and Processing of the Arrays}

DNA samples (PCR products dissolved in water, $250 \mu \mathrm{g} / \mathrm{mL}, 10 \mu \mathrm{L}$ ) were transferred to a $96-$ well plate and mixed with an equal volume of spotting buffer (20\% glycerol in TE buffer, $\mathrm{pH}$ 7.4). Samples are printed onto poly-Llysine-coated glass slides (Cel Associates, Pearland, TX, USA) with the SP$\mathrm{BIO}^{\mathrm{TM}}$ (MiraiBio) $(7,10)$ using eight $400-\mu \mathrm{m}$ diameter pins mounted in a $4 \times$ 2 pattern (9-mm pin spacing). The instrument was configured so that the contents of the 96-well plate would be printed six times in $10 \times 8$ blocks $(72$ spots/block, eight blocks total). The pitch of the spots was $800 \mu \mathrm{m}$. After printing was complete, the glass slides were heated at $80^{\circ} \mathrm{C}$ for $1 \mathrm{~h}$ in an air oven. The spots of glycerol disappeared completely in this time, as viewed under a microscope. The slides were hydrated by incubation at approximately $50^{\circ} \mathrm{C}$ in a sealed container with a moist paper towel for 1-5 min and were UV irradiated $\left(120 \mathrm{~mJ} / \mathrm{cm}^{2}\right.$; Spectrolinker ${ }^{\mathrm{TM}}$ XL-1000; Spectronics, Westbury, NY, USA). The slides were blocked by reaction with succinic anhydride $(2.5 \mathrm{~g}$ dissolved in $157.5 \mathrm{~mL}$ n-methyl-2pyrrolidinone and $17.5 \mathrm{~mL} 0.2 \mathrm{M}$ sodium borate buffer, $\mathrm{pH} 8.0$ ) for $10 \mathrm{~min}$. The slides were washed immediately with water and were denatured in boiling water for $2 \mathrm{~min}$ in a microwave oven. The slides were washed in ethanol $(100 \%)$ and dried at room tem perature.

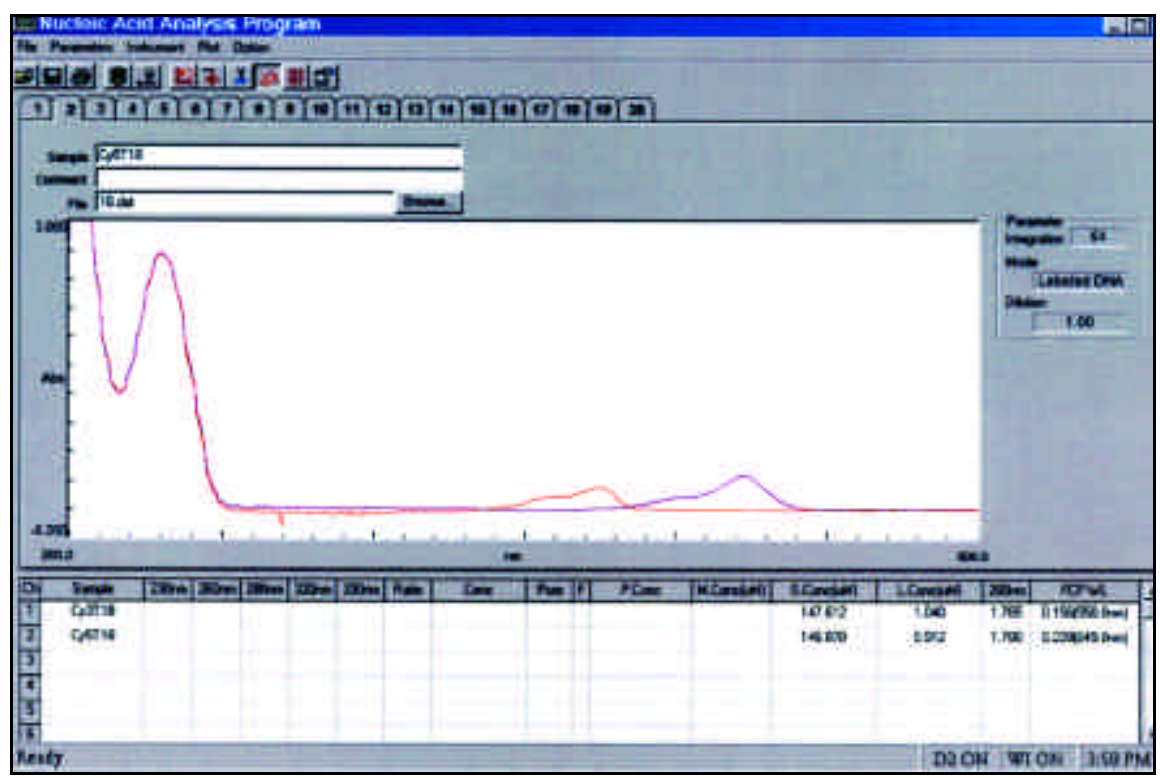

Figure 4. Absorbance spectra (2- $\mu \mathrm{L}$ cuvet, GeneSpec III) of the cDNA product of the reverse transcription of the yeast mRNA with Cy3-labeled (red line) and Cy5-labeled (blue line) Tr. The ratio of the two concentrations (O. Conc./L. Conc.) is a measure of the average length of the cDNA produced with the dye-labeled reverse transcription primer.

\section{Hybridization and Scanning}

The cDNA sample $(1 \mu \mathrm{g})$ to be analyzed was diluted with hybridization buffer $(5 \times \mathrm{SSC}, 0.5 \% \mathrm{SDS}, 25 \mu \mathrm{L}$ total volume), heated to $95^{\circ} \mathrm{C}$ for $2-3 \mathrm{~min}$, and cooled to room temperature. The hybridization solution ( $20 \mu \mathrm{L} /$ array $)$ was transferred onto the array with a hand pipet and was covered with a glass coverslip $(24 \times 60 \mathrm{~mm}, 0.0139$ $\mu \mathrm{L} / \mathrm{mm}^{2}$ ), being careful not to create bubbles between the coverslip and the glass slide. The samples were heated to $65^{\circ} \mathrm{C}$ for more than $10 \mathrm{~h}$ while sealed in an airtight plastic box together with a few wet paper towels. After the hybridization was complete, the coverslip was removed by washing in $2 \times \mathrm{SSC}$, $0.1 \%$ SDS solution at room temperature, and the arrays were washed in the following buffers in this order $(400 \mathrm{~mL}$ each step): $(i)$ twice in $2 \times \mathrm{SSC}, 0.1 \%$ $\mathrm{SDS}$ at room temperature; (ii) twice in $0.2 \times \mathrm{SSC}, 0.1 \% \mathrm{SDS}$ at room temperature; (iii) twice in $0.2 \times \mathrm{SSC}, 0.1 \%$ SDS at $40^{\circ} \mathrm{C}-60^{\circ} \mathrm{C}$; (iv) twice in $0.2 \times \mathrm{SSC}$, $0.1 \%$ SDS at room temperature; and $(v)$ rinsed briefly at room temperature with $0.05 \%$ SSC. The arrays were centrifuged to dryness at $5^{\circ} \mathrm{C}$ at $65 \times \mathrm{g}$. Images were recorded with a GenePix $4000 \mathrm{~b}$ microarray scanner and were analyzed with GenePix Pro software (both from Axon, Union City, CA, USA).

\section{RESULTS AND DISCUSSION}

Absorbance spectra of the labeled yeast cDNA, recorded with the GeneSpec III, shows both a peak from nucleic acid at $260 \mathrm{~nm}$ and a peak from either $\mathrm{Cy} 3(\lambda=550 \mathrm{~nm})$ or $\mathrm{Cy} 5(\lambda=649$ $\mathrm{nm})$, indicating that the fluorescent dye 
has been incorporated into the cDNA (Figures 3 and 4). The concentration of the DNA is automatically calculated and displayed by the GeneSpec software, along with the concentration of the dye label and nucleic acid bases present in the sample (Table 2). The concentration of the nucleic acid base is calculated from the absorbance at 260 $\mathrm{nm}$, assuming equal concentrations of all four bases $(0.25$ is entered as the number of each base, and the average extinction coefficient for the four bases is calculated). The average molecular weight of the reverse transcription product can be calculated from the spectra of cDNA prepared with the dye-labeled primer by dividing the concentration of nucleic acid base by the concentration of the dye label. In this case, the average molecular weight of the transcript is calculated to be 142 bases from the Cy3-labeled primer and 163 bases from the Cy5-labeled primer. It is interesting to see that the average lengths of the two populations of cDNA are slightly different. It is not clear from this data, however, if this difference in length is statistically significant. The spectra of the cDNA labeled with Cy-labeled dUTP yield information concerning the labeling efficiency (the ratio of the concentration of dyes to the concentration of nucleic acid base) of the reverse transcription; one $\mathrm{Cy} 3$ was incorporated every 61 bases, and one Cy5 was labeled every 51 bases in this example. The efficiency of the labeling is 2.7 times higher using the triphosphate labeling method than the dye-labeled primer method.

The effect of labeling efficiency on the results of competitive hybridization to a microarray was evaluated by hybridization of the labeled cDNA sam ples to microarrays of yeast cDNA (5). The Cy-labeled cDNAs were hybridized to the arrays ( $1 \mu \mathrm{g}$ cDNA was used per hybridization). The arrays were imaged (Figures 5 and 6) with the microarray scanner and the images were analyzed. The average fluorescent hybridization signal intensity of each array in both the 532- and 635-nm channels was com pared by finding the mean average of the mean signal intensity of each spot (after background subtraction) and are presented in Table 2 for comparison to the GeneSpec III data.

The average hybridization signal intensity measured in two different hybridization experiments correlates with the labeling efficiency of the cDNA used in the hybridization measured with the GeneSpec III. Increased fluorescence labeling efficiency has the effect of increasing the average hybridization signals observed from the corresponding array. This observation suggests that the simple GeneSpec III measurement can be used to predict the average hybridization signal intensity measured in an array experiment. Thus, the smallvolume absorbance measurements made possible by the GeneSpec III allows investigators to better monitor the concen- a)

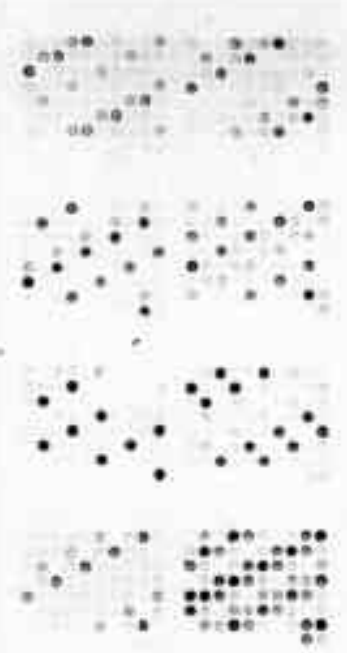

b)
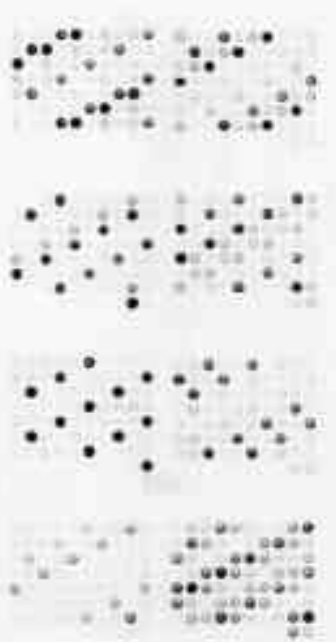

c)
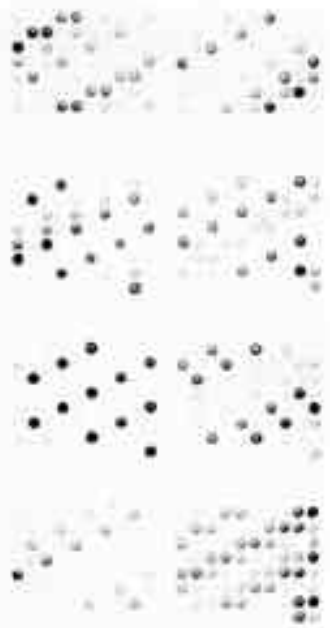

d)
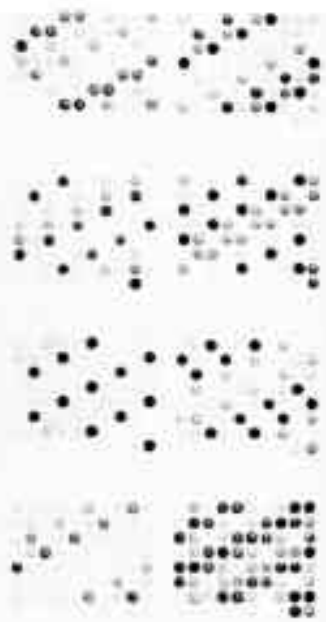

Figure 5. Images of the microarrays that were used to generate the $\mathrm{Cy} 3$ signal intensity data (532nm excitation) that are presented in Table 1. ( $a$ and $b$ ) Images of arrays produced by hybridization to the cDNA that was prepared with the Cy-labeled primers. (c and d) Images of arrays produced by hybridization to the cDNA that was labeled with the Cy-labeled triphosphates. 
a)

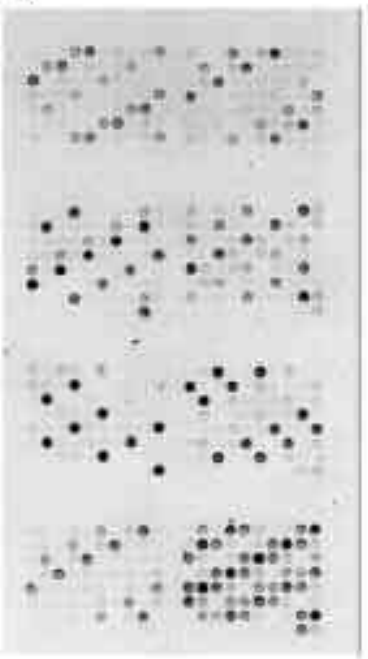

b)

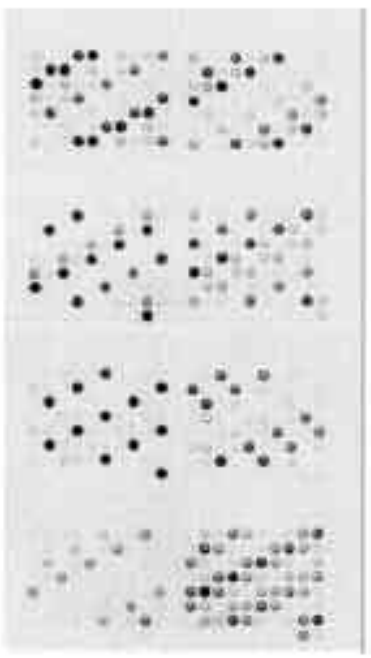

c)

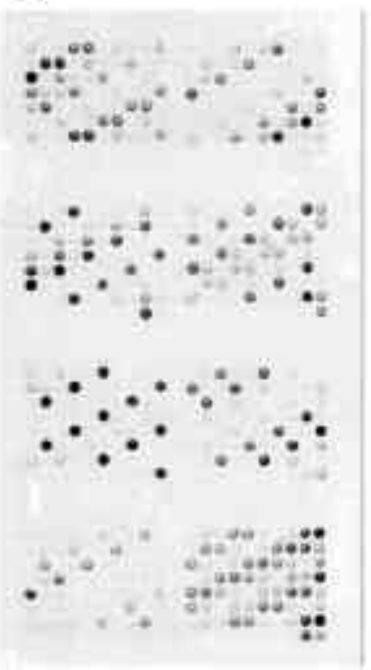

d)

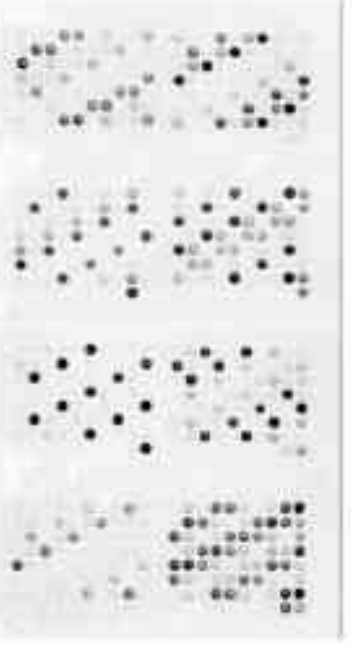

3.Freeman,W.M., D.J. Robertson, and K.E. Vrana. 2000. Fundamentals of DNA hybridization arrays for gene expression. BioTechniques 29:1042-1055.

4.Hegde, P., R. Qi, K. Abernathy, C. Gay, S. Dharap, R. Gaspard, J.E. Hughes, E. Snesrud, N. Lee, and J. Quackenbush. 2000. A concise guide to cDNA microarray analysis. BioTechniques 29:548-562.

5.Lockhart, D.J. and E.A. Winzeler. 2000. Genomics, gene expression and DNA arrays. Nature 405:827-836.

6.Ohyama, H., X. Zhang, Y. Kohno, I. Alevizos, M. Posner, D.T. Wong, and R. Todd. 2000. Laser capture microdissection-generated target sample for high-density oligonucleotide array hybridization. BioTechniques 29:530-536.

7.Sakai, K., H. Higuchi, K. Matsubara, and K. Kato. 2000. Microarray hybridization with fractionated cDNA: enhanced identification of differentially expressed genes. Anal. Biochem. 287:32-37.

8.Sambrook, J., E.F. Fritsch, and T. Maniatis. 1989. Molecular Cloning, 2nd ed. CSH Laboratory Press, Cold Spring Harbor, NY.

9.Schena, M., D. Shalon, R.W. Davis, and P.O. Brown. 1995. Quantitative monitoring of gene expression patterns with a complementary DNA microarray. Science 270:467-470.

10. Yoshikawa, T., Y. Nagasugi, T. Azuma, M. Kato, S. Sugano, K. Hashimoto, Y. Masuho, M. Muramatsu, and N. Seki. 2000. Isolation of novel mouse genes differentially expressed in brain using cDNA microarray. Biochem. Biophys. Res. Commun. 275:532-537.

Address correspondence to:

Dr. William H. Chapman Jr.

MiraiBio, Inc.

1201 Harbor Bay Parkway

Suite 150

Alameda, CA 94502, USA

e-mail:wchapman@miraibio.com

Figure 6. Images of the microarrays that were used to generate the Cy5 signal intensity data (635nm excitation) that are presented in Table 1. Images of arrays produced by hybridization to the cDNA that was prepared with the Cy-labeled primers. (c and d) Images of arrays produced by hybridization to the cDNA that was labeled with the Cy-labeled triphosphates.

tration of samples that are being used in a microarray experiment and should allow for the more efficient use of arrays available for the experiment.

\section{ACKNOWLEDGMENTS}

We would like to thank Takeshi Sasayama, Mitsuhiro Tachibana, and Taku Tamura for help with the array experiments. The yeast DNA was a gift from Hitachi DNA Chip Research Laboratory (Yokohama, Japan).

\section{REFERENCES}

1.Ausubel, F.M., R. Brent, R.E. Kingston, D.D. Moore, J.G. Seidman, J.A. Smith, and K. Struhl. 1992. Short Protocols in Molecular Biology, 2nd ed. John Wiley \& Son, New York.

2.Chapman,W.H. 2000. Quantitative UV spectral analysis of aqueous samples as small as 1 $\mu \mathrm{L}$. Am. Biotechnol. Lab. 18:30.
For reprints of this or any other article, contact Reprints@BioTechniques.com 